\title{
Association of common variants in JAK2 gene with reduced risk of metabolic syndrome and related disorders
}

\author{
Alberto Penas-Steinhardt ${ }^{1 *}$, Mariana L Tellechea ${ }^{11,2+}$, Leonardo Gomez-Rosso ${ }^{3}$, Fernando Brites ${ }^{3}$, \\ Gustavo D Frechtel ${ }^{2,4}$ and Edgardo Poskus ${ }^{2}$
}

\begin{abstract}
Background: Disturbances in leptin and insulin signaling pathways are related to obesity and metabolic syndrome (MS) with increased risk of diabetes and cardiovascular disease. Janus kinase 2 (JAK2) is a tyrosine kinase involved in the activation of mechanisms that mediate leptin and insulin actions. We conducted a population cross-sectional study to explore the association between two common variants in JAK2 gene and MS related traits in 724 Argentinean healthy male subjects.
\end{abstract}

Methods: A total of 724 unrelated men aged $37.11 \pm 10.91 \mathrm{yr}$ were included in a cross-sectional study. Physical examination, anthropometric measurements and biochemical analysis were determined by a standardized protocol. rs7849191 and rs3780378 were genotyped. Analyses were done separately for each SNP and followed up by haplotype analysis.

Results: rs7849191 and rs3780378 were both associated with reduced risk of MS $[p=0.005 ; \mathrm{OR}(95 \% \mathrm{Cl})=0.52$ $(0.33-0.80)$ and $\mathrm{p}=0.006 ; \mathrm{OR}(95 \% \mathrm{Cl})=0.59(0.40-0.86)$ respectively, assuming a dominant model]. rs3780378 T allele was associated with triglyceridemia values under $150 \mathrm{mg} / \mathrm{dl}[\mathrm{p}=0.007 ; \mathrm{OR}(95 \% \mathrm{Cl})=0.610(0.429-0.868)]$ and $\Pi$ carriers showed lower triglycerides $(p=0.017)$, triglycerides/HDL-C ratio $(p=0.022)$ and lipid accumulation product ( $p=0.007$ ) compared to allele $C$ carriers. The two-SNPs-haplotype analysis was consistent with single locus analysis.

Conclusions: It was found for the first time, significant associations of JAK2 common variants and related haplotypes with reduced risk of MS. These findings could be explained by the role of JAK2 in insulin and/or leptin signaling.

\section{Background}

The metabolic syndrome (MS) is a constellation of cardiometabolic risk factors including central obesity, insulin resistance (IR), hypertension, hyperglycemia, and dislipidemia $[1,2]$. Insulin resistance (IR) is probably the principal cause of the MS [3,4]. Over the past decades, a sustained worldwide increase in the incidence of MS has taken place, associated with the global epidemic of obesity and type 2 Diabetes Mellitus (DM2) [5].

\footnotetext{
* Correspondence: pufetin@gmail.com

† Contributed equally

1Humoral Immunity Institute "Prof. Ricardo A. Margni" (IDEHU), National Research Council (CONICET) \& Chair of Immunology, School of Pharmacy and Biochemistry, University of Buenos Aires (UBA) - Argentina Full list of author information is available at the end of the article
}

Janus kinase 2 (JAK2) is a nonreceptor tyrosine kinase recruited by receptors that lack intrinsic kinase activity [6]. The JAK/STAT (signal transducer and activator of transcription) pathway transmits a wide range of cytoplasmic signals from cytokines, growth factors and hormones that bind to specific cell surface receptors [7]. Suppressor of cytokine signaling (SOCS) proteins are known to act as negative regulators of cytokine action via inhibition of these pathways. There is a growing body of evidence that supports a role for specific SOCS members in the development of IR [8].

Insulin and leptin are major signals to regulate energy homoeostasis and body adiposity $[9,10]$. After binding to its receptor, leptin induces activation of JAK2 and

\section{() Biomed Central}


subsequent phosphorylation of specific tyrosines on the receptor [11]. The cytokine-like hormone leptin receptor is a member of the class I cytokine receptor family found in many tissues in several alternatively spliced forms $[12,13]$. The long isoform (LepRb) transduces signal mainly through the JAK2/STAT3 pathway. JAK2 also phosphorylates Insulin Receptor Substrates 1 and 2 (IRS-1 and IRS-2) integral to insulin and leptin action [14]. Insulin carries out its biological effects through the phosphorylation of IRS-1 and IRS-2 and it is also well documented the cross-talk between the insulin and leptin signal transduction pathways. Leptin was reported to induce IRS-1 and IRS-2 phosphorylation [15].

Recently, although not significant at levels which took account of multiple testing, suggestive associations between two single nucleotide polymorphisms (SNPs) of JAK2 gene and central fat, waist circumference and serum lipid variables have been reported [16]. Replication is fundamental for deciding that an observed association is likely not due to chance [17]. Therefore, the aim of this study was to explore associations between these two SNPs of JAK2 and their predicted haplotypes on MS and related phenotypes and quantitative metabolic traits.

\section{Methods \\ Subjects}

The total sample includes 724 unrelated men of selfreported European ancestry, especially from Spain and Italy, living in Buenos Aires metropolitan area. Individuals were selected from a cross-sectional study. Participants were recruited, between April 2006 and April 2008, from the Departement of Haemotherapy of the Hospital "José de San Martín" of the University of Buenos Aires. Ages ranged between 18 to 65 years. Clinical characteristics of the sample are shown in Table 1. All subjects were non diabetic with normal findings on medical examination and blood count. This work was carried out in accordance with the Declaration of Helsinki, and approved by the Ethic Committee of our Hospital. All subjects gave their written consent previously to participate in the study (clinical characteristics are summarized in Table 1).

\section{Clinical measurements}

Anthropometric measurements (height, weight and waist circumference) and Systolic (SBP) and Diastolic (DBP) blood pressure were determined by a standardized protocol in every subject.

After a 12-h overnight fast, fasting blood samples were drawn in every individual from an antecubital vein. Total cholesterol (TC), triglycerides (TG), and high-density lipoprotein (HDL-C) were determined in serum by enzymatic methods using commercial kits (Roche Diagnostics,
Table 1 Clinical characteristics of the sample

\begin{tabular}{lllll}
\hline & Mean & SD & Phenotype & Prevalence (\%) \\
\hline Age (yr) & 37.11 & 10.91 & HTG & 31.1 \\
BMI (kg/m2) & 28.20 & 4.40 & HW & 27.8 \\
WC (cm) & 96.15 & 12.26 & Decreased HDL-C & 45.6 \\
SBP (mmHg) & 126.29 & 11.02 & Abdominal obesity & 31.3 \\
DBP (mmHg) & 80.11 & 7.38 & Obesity & 29.3 \\
TC (mg/dl) & 187.45 & 40.75 & IFG & 18.0 \\
LDL-C (mg/dl) & 118.52 & 34.89 & MS & 24.1 \\
HDL-C (mg/dl) & 41.25 & 10.66 & & \\
TG (mg/dl) & 138.77 & 95.97 & & \\
LAP & 52.74 & 6.72 & & \\
TG/HDL-C & 3.86 & 3.73 & & \\
FPG (mg/dl) & 91.87 & 12.23 & & \\
Fasting insulin & 16.18 & 9.27 & & \\
HOMA-IR & 2.07 & 1.16 & & \\
\hline
\end{tabular}

$\mathrm{n}=724$. DBP, diastolic blood pressure; FPG, fasting plasma glucose; HDL-C, high-density lipoprotein cholesterol; HOMA-IR, homeostasis model assessment of insulin resistance; HW, hypertriglyceridemic waist; IR, insulin resistance; LDLC, low-density lipoprotein cholesterol; SBP, systolic blood pressure; TC, total cholesterol; TG, triglycerides; LAP = lipid accumulation product; WC, waist circumference; $\mathrm{HTG}=$ Hypertriglyceridemia; $\mathrm{HW}=$ hypertriglyceridemic waist: IFG = impaired fasting glucosa; MS = metabolic syndrome

Mannheim, Germany) in a Hitachi 727 autoanalyzer. All determinations were performed using standardized procedures. Intra assay-CV (coefficient of variation) for TG and total cholesterol were 1.3 and $1.1 \%$, respectively. Inter assay-CVs were $2.4 \%$ and $1.5 \%$, respectively. Fasting plasma glucose (FPG) was determined by a glucose-oxidase method (Roche Diagnostics, Mannheim, Germany) in a Hitachi 727 autoanalyzer. Intra- and inter-CVs were 0.9 and $1.8 \%$, respectively. Fasting serum insulin was measured by radioimmunoassay with a commercial kit (Human Insulin Specific RIA kit, Linco Research Inc., St. Louis, MO, USA) by counting on a gamma counter (DPC Gambyt CR, Los Angeles, USA), with a lower detection limit of $2 \mu \mathrm{U} / \mathrm{ml}$, intra- and inter-CVs being $<1$ and $<$ $7.43 \%$, respectively. Cross-reactivity was less than $0.2 \%$ to intact human proinsulin.

\section{Calculations}

Insulin sensitivity was assessed with Homeostasis Model Assessment of insulin resistance (HOMA-IR) using the software HOMA Calculator v.2.2.2 for Windows [18] Low-density lipoprotein cholesterol (LDL-C) was calculated using the Friedewald formula [19]. In addition, TG/HDL-C ratio and lipid accumulation product (LAP) were calculated. LAP, an index of lipid overaccumulation associated with cardiovascular risk and identification of diabetes, was defined (for men) as (waist circumference $(\mathrm{WC})[\mathrm{cm}]-65) \times(\mathrm{TG}$ concentration $[\mathrm{mmol} / \mathrm{L}])[20]$.

Each subject was assessed for the presence of 1) Obesity according to body mass index $(\mathrm{BMI}) \geq 30.0 \mathrm{~kg} / \mathrm{m}^{2}$ 
[21]; 2) abdominal obesity according to $\mathrm{WC}>102 \mathrm{~cm}$ [22]; 3) hypertriglyceridemia (HTG) according to fasting TG $\geq 150 \mathrm{mg} / \mathrm{dl}$ or drug treatment; 4) hypertriglyceridemic waist (HW) according to $\mathrm{TG} \geq 150 \mathrm{mg} / \mathrm{dl}+\mathrm{WC}$ $\geq 90 \mathrm{~cm}$; 5) decreased HDL-C according to fasting HDL-C $<40 \mathrm{mg} / \mathrm{dl}$ or drug treatment; 6) Impaired Fasting Glucose (IFG) according to Fasting Plasma Glucose $(\mathrm{FPG}) \geq 100 \mathrm{mg} / \mathrm{dl}$; and 7) MS using the American Heart Association/National Heart, Lung, and Blood Institute (AHA/NHLBI) 2005 criteria [23]. Participants who had FPG $\geq 126 \mathrm{mg} / \mathrm{dl}$ were excluded from the study [24].

\section{SNP selection and genotyping}

Since replication of findings is an important requirement for genetic association studies, we studied two SNPs (rs7849191 and rs3780378) based on a previous report of $\mathrm{Ge}$ et al [16]. The linkage disequilibrium (LD) analysis (Haploview 4.1 [25]) of the $142.8 \mathrm{~kb}$ region under study showed that both SNPs capture $20 \%$ of alleles with minor allele frequency (MAF) $\geq 10 \%$ at $r^{2} \geq$ 0.8 [we downloaded information from The International HapMap Project web site (http://www.hapmap.org) (HapMap Data Rel 28 PhaseII+III, August10) from the Caucasian European Utah dataset (CEPH)]. Of note, rs7849191 is not in LD with other SNPs and rs3780378 is in LD with other 17 SNPs (rs2230724, rs4372063, rs10815144, rs7037207, rs2149556, rs1328918, rs7034753, rs7875908, rs10115312, rs7023146, rs7857730, rs7847294, rs6476939, rs7032785, rs7043371, rs1328917, rs3780378).

Genomic DNA was isolated from peripheral blood according to standard procedures. The two SNPs were genotyped by KBiosciences, Hoddesdon, Herts., UK, using the KASPar system. This is a fluorescence based allele-specific PCR procedure with improved robustness and discriminating power over conventional ARMS, (http://www.kbioscience.co.uk/chemistry/chemistryintro.htm). Genotyping accuracy was assessed by inclusion of duplicates and negative controls. Genotyping success rate was $100 \%$ for rs7849191 and $98.7 \%$ rs3780378. Our lab randomly sampled $10 \%$ of the subjects for sequencing to corroborate the initial findings. Using these criteria consistency was 100\%.

For each individual case-control study power estimations were performed for single-point allelic effects, with an odds ratio of 1.5 at a nominal significance level of 0.05 [26]. Power estimation was found to be less than $80 \%$ to detect effects on MS. However, to detect effects on HTG, HW, obesity or abdominal obesity, power estimation was found to be between 81 and 99\% assuming a dominant model and less than $80 \%$ assuming a recessive model for rs7849191; and between 80 and $98 \%$ assuming a recessive model and less than $80 \%$ assuming a dominant model for rs3780378. The power estimation was found to be between 85 and 99\% to detect effects of rs7849191 and rs3780378 on decreased HDL-C.

\section{Statistical analysis}

Deviation of the genotype distribution from the HardyWeinberg equilibrium (HWE) was tested using Chi square $\left(\chi^{2}\right)$ test. We calculated odds ratio (OR) and 95\% confidence intervals $(95 \% \mathrm{CI})$. Analyses were done separately for each SNP and followed up by haplotype analysis. For individual SNP the statistical difference in genotype distribution and allele frequencies among the groups for qualitative variables was assessed by the Fisher exact test. Binary logistic regression was used to adjust for possible confounding variables. Quantitative data were expressed as means \pm SD. For comparison of continuous variables we conducted one-way ANOVA with Levine's Test for equality of variances. Otherwise, we used Welch tests. Multiple linear regression analysis was used to adjust for possible confounding variables. Furthermore, genotype status and age subgroup (2 subgroups according to the average age: $<37$ and $\geq 37$ years old) were used as factors in a Multivariate linear regression analysis to determine interaction of age and genotype.

We reconstructed the two SNP -haplotypes using PHASE 2.1 [27]. The haplotype frequencies were estimated using the programs PHASE 2.1 and Thesias $[28,29]$ We analyzed haplotypic effects using the Thesias software and conventional statistical methods as well. A Fisher exact test was used to compare haplotype frequencies. The effects of a particular haplotype load (0: no copies of the particular haplotype; 1: 1 copy; and 2: 2 copies) on continuous variables were tested using a linear regression.

A two sided p-value less than 0.05 was considered statistically significant. Since our results represent a basic replication of previously reported findings, p-values were not corrected for the number of tests performed. However, we follow the recommendations of van den Oord and Sullivan [30], which suggest that a level of significance of $\mathrm{p}=0.01$ on average control the false discovery rate at 0.10 . Note that after applying the Bonferroni correction for multiple tests, the significance level was $\mathrm{p}$ $<0.025(0.05 / 2$ for 2 loci $)$. The significance level was $\mathrm{p}$ $<0.01(0.05 / 4)$ for correction for multiple tests in haplotype analyses (4 haplotypes for 2 loci). Statistical analyses were conducted using the program for Statistical Package for the Social Sciences, version 12.0 for Windows (SPSS, Inc., Chicago, IL).

\section{Results}

Both rs7849191 $\left(\chi^{2}=1.52, \mathrm{p}=0.22\right)$ and $\operatorname{rs} 3780378\left(\chi^{2}\right.$ $=0.086, \mathrm{p}=0.77)$ were in HWE. Genotypic frequencies 
were as follow: rs7849191: CC 0.40 CT 0.45 and TT 0.15; and rs3780378: TT 0.26 TC 0.49 and CC 0.25 . The MAFs were 0.037 and 0.49 for rs7849191 and rs3780378 respectively, similar to previously reported in Caucasians (http://www.ncbi.nlm.nih.gov/snp/).

\section{Single-Locus Analyses \\ Association with MS}

SNPs rs7849191 and rs3780378 were both associated with MS. Age adjusted association between rs7849191 and MS was not significant, but association between rs3780378 and MS remained significant taking into account the effects of age $(p=0.002)$. C allele of rs7849191 and $\mathrm{T}$ allele of rs3780378 showed a lower risk for MS assuming both dominant and recessive model. Adjusted analysis confirmed these associations (Table 2). Note that associations with MS with both rs7849191 and rs3780378 under a dominant model, even accounting for the effects of covariates, were significant at levels that take into account multiple testing.

\section{Association with phenotypes and quantitative traits related to lipid metabolism}

SNP rs3780378 was associated with TG values under $150 \mathrm{mg} / \mathrm{dl}(\mathrm{p}=0.013$ and $\mathrm{p}=0.006$ after adjusting for age). $\mathrm{T}$ allele carriers showed a lower risk for HTG than the CC genotype carriers $(\mathrm{OR}=0.61$ [95\% CI $=0.43$ $0.87])$ at levels that take into account multiple testing even after correcting for covariates. Furthermore, rs3780378 was associated with HW $(\mathrm{p}=0.037$ and $\mathrm{p}=$
0.021 after controlling for age). Moreover, rs3780378T carriers, assuming both a dominant and a recessive model, showed lower risk of HW with borderline nominal significance. Age-adjusted analysis confirmed a significant effect on HW risk (Table 2).

We also were able to show significant differences between rs3780378 genotypes in TG $(p=0.001)$, TG/ HDL-C ratio ( $p=0.004)$ and LAP $(p=0.003)$. However, these observations were not confirmed taking into account the effects of age (Table 3). TT genotype carriers of rs3780378 compared to allele $\mathrm{C}$ carriers (recessive model), showed a lower TG, LAP and TG/ HDL-C ratio. Adjusted analysis confirmed the associations at levels that take into account multiple testing (Table 3). Associations under a dominant model were significant only taking into account age (data not shown).

The association of rs3780378 genotype with TG, LAP and TG/HDL-C was not age-dependent $(\mathrm{p}=0.059, \mathrm{p}=$ 0.213 and $\mathrm{p}=0.111$ for $\mathrm{rs} 3780378$ genotype- by-age interaction respectively).

The SNP rs3780378 was not associated with HDL-C or LDL-C. rs7849191 was not associated with categorical or continuous variables related to lipid metabolism.

\section{Association with obesity and obesity-related quantitative traits}

We found neither associations between both SNPs under study and obesity or abdominal obesity; nor we were able to show significant differences among genotypes in BMI, WC, fasting insulin or HOMA-IR.

Table 2 Association between individual JAK2 SNPs, Metabolic Syndrome and related phenotypes

\begin{tabular}{|c|c|c|c|c|c|c|}
\hline & MS negative & MS positive & OR (IC 95\%) & $\mathrm{p}$ & $p^{a}$ & $p^{b}$ \\
\hline \multicolumn{7}{|l|}{ rs7849191 } \\
\hline TT vs. TC vs. CC & 69 vs. 241 vs. 226 & 38 vs. 76 vs. 57 & - & 0.009 & ns & ns \\
\hline$C C+C T$ vs. $T$ & 467 vs. 69 & 133 vs. 38 & $0.517(0.333-0.803)$ & 0.005 & 0.001 & 0.002 \\
\hline CC vs. $C T+\Pi$ & 226 vs. 310 & 57 vs. 114 & $0.686(0.478-0.984)$ & 0.048 & 0.011 & 0.034 \\
\hline \multicolumn{7}{|l|}{ rs3780378 } \\
\hline TT vs. TC vs. CC & 149 vs. 269 vs. 121 & 33 vs. 83 vs. 57 & - & 0.008 & 0.002 & ns (0.096) \\
\hline $\mathrm{TT}+\mathrm{TC}$ vs. CC & 418 vs. 121 & 116 vs. 57 & $0.589(0.404-0.858)$ & 0.006 & 0.001 & 0.007 \\
\hline \multirow[t]{2}{*}{ TT vs. TC+ CC } & 149 vs. 390 & 33 vs. 140 & $0.617(0.404-0.942)$ & 0.027 & 0.020 & 0.022 \\
\hline & HTG negative & HTG positive & OR (IC 95\%) & $\mathrm{p}$ & $\mathbf{p}^{a}$ & $\mathbf{p}^{\mathrm{b}}$ \\
\hline \multicolumn{7}{|l|}{ rs3780378 } \\
\hline TT vs. TC vs. CC & 139 vs. 250 vs. 108 & 48 vs. 108 vs. 71 & - & 0.013 & 0.006 & ns (0.082) \\
\hline TT +TC vs. CC & 389 vs. 108 & 136 vs. 71 & $0.610(0.429-0.868)$ & 0.007 & 0.002 & 0.011 \\
\hline \multirow[t]{2}{*}{ TT vs. TC+ CC } & 139 vs. 358 & 48 vs. 179 & - & & ns & ns \\
\hline & HW negative & HW positive & OR (IC 95\%) & $\mathrm{p}$ & $\mathbf{p}^{\mathrm{a}}$ & $\mathbf{p}^{\mathrm{b}}$ \\
\hline \multicolumn{7}{|l|}{ rs3780378 } \\
\hline TT vs. TC vs. CC & 145 vs. 257 vs. 118 & 41 vs. 101 vs. 61 & - & 0.037 & 0.021 & ns (0.082) \\
\hline TT +TC vs. CC & 402 vs. 118 & 142 vs. 61 & $0.683(0.475-0.983)$ & 0.044 & 0.016 & ns (0.07) \\
\hline TT vs. TC+ CC & 145 vs. 375 & 41 vs. 172 & $0.655(0.442-0.969)$ & 0.037 & 0.033 & ns (0.05) \\
\hline
\end{tabular}

\footnotetext{
${ }^{a}$ Age adjusted; ${ }^{\text {b }}$ Age and BMI adjusted. MS = metabolic syndrome; $\mathrm{HTG}=$ Hypertriglyceridemia; HW = hypertriglyceridemic waist; ns = not significant.
} 
Table 3 Single locus analysis of quantitative metabolic traits and surrogate measures of IR

\begin{tabular}{|c|c|c|c|c|c|c|}
\hline \multicolumn{7}{|l|}{ rs3780378 } \\
\hline & $T T(n=186)$ & $\mathrm{TC}(\mathrm{n}=358)$ & $C C(n=179)$ & & & \\
\hline & Mean \pm SD & Mean \pm SD & Mean \pm SD & $p$ & $p^{a}$ & $p^{b}$ \\
\hline TG $(\mathrm{mg} / \mathrm{dL})$ & $120.61 \pm 67.76$ & $144.04 \pm 104.745$ & $150.17 \pm 106.38$ & $0.001^{c}$ & ns & ns \\
\hline TG/HDL-C & $3.27 \pm 2.60$ & $3.99 \pm 3.84$ & $4.39 \pm 4.68$ & $0.004^{c}$ & ns & ns \\
\hline \multirow[t]{3}{*}{ LAP } & $44.42 \pm 37.72$ & $54.58 \pm 49.32$ & $58.89 \pm 50.77$ & $0.003^{c}$ & ns & ns \\
\hline & $\pi(n=187)$ & $\mathrm{TC}+\mathrm{CC}(\mathrm{n}=537)$ & & & & \\
\hline & Mean \pm SD & Mean \pm SD & $p$ & $p^{a}$ & $p^{b}$ & \\
\hline TG $(\mathrm{mg} / \mathrm{dL})$ & $120.61 \pm 67.76$ & $146.09 \pm 105.23$ & $0.00017^{c}$ & 0.006 & 0.009 & \\
\hline TG/HDL-C & $3.27 \pm 2.60$ & $4.13 \pm 4.13$ & $0.001^{c}$ & 0.008 & 0.011 & \\
\hline LAP & $44.42 \pm 37.72$ & $56.00 \pm 49.80$ & $0.0011^{c}$ & 0.004 & 0.006 & \\
\hline
\end{tabular}

rs3780378 recessive model. ANOVA was performed for normal-distributed data and Welch otherwise. Multiple linear regression analysis was used to adjust for possible confounding variables. Linear regression analysis was performed with log transformed values for phenotypes deviating from normality. LAP = lipid accumulation product. ${ }^{\mathrm{c}}=$ Welch $\mathrm{p}$ value. ${ }^{\mathrm{a}}$ Age adjusted; ${ }^{\mathrm{b}}$ Age and BMI adjusted.

\section{Haplotype Analyses}

The inferred two-SNP-haplotype frequencies of rs7849191 and rs3780378 in that order were as follow: CC 0.18, haplotype CT 0.45 , haplotype TC 0.32 and haplotype TT 0.05 . In order to reduce the degree of freedom, the TT haplotype, with a frequency less than $5 \%$, was removed from the analysis. We found 2-df association with MS ( $\mathrm{p}=0.011$ ) when compared the overall frequency differences across three possible two-SNPhaplotypes. We could not find any other significant 2-df association. In a separate analysis, each haplotype was compared with haplotype TC. Haplotype CT (carring both protective alleles) was associated with MS even taking into account correction for multiple comparisons (CT vs. TC $\mathrm{p}=0.00054$, age adjusted $\mathrm{p}=0.000071$ and age and BMI adjusted $\mathrm{p}=0.00010)$. Besides, significant difference in haplotype frequencies was found for TG values under $150 \mathrm{mg} / \mathrm{dl}$ (CT vs. TC p $=0.0069$ and CC vs. TC $\mathrm{p}=0.040)$ and HW (CT vs. TC; $\mathrm{p}=0.047$ and CC vs. TC $\mathrm{p}=0.0058)$. Adjusted analysis confirmed these associations (TG values under $150 \mathrm{mg} / \mathrm{dl}$ : CT vs. $\mathrm{TC}$ age adjusted $\mathrm{p}=0.026$ and age and BMI adjusted $\mathrm{p}$ $=0.0055 ; \mathrm{CC}$ vs. TC age adjusted $\mathrm{p}=0.0023$ age and BMI adjusted $\mathrm{p}=0.068$; and HW: CT vs. TC age adjusted $\mathrm{p}=0.019$ and age and BMI adjusted $\mathrm{p}=0.047$; $\mathrm{CC}$ vs. TC age adjusted $\mathrm{p}=0.0029$ and age and BMI adjusted $\mathrm{p}=0.010)$. No association was found between the inferred two -SNP-haplotype and another obesity or lipid metabolism related phenotypes.

Two-SNP haplotype analysis of quantitative metabolic traits showed association of haplotype CT with TG (CT vs. TC $\mathrm{p}=0.042$, age adjusted $\mathrm{p}=0.024$ and age and BMI adjusted $\mathrm{p}=0.023$ ) and TG/HDL- $\mathrm{C}$ ratio (CT vs. $\mathrm{TC} \mathrm{p}=0.019, \mathrm{p}=0.044$ and age and $\mathrm{BMI}$ adjusted $\mathrm{p}=$ 0.027). Association remained significant after adjustment. Association of haplotype CT with LAP became significant only after age adjustment (CT vs. TC p = 0.059 , age adjusted $\mathrm{p}=0.061$ and age and BMI $\mathrm{p}=$
0.017) and besides, association of haplotype $C C$ with LAP was observed ( $C C$ vs. TC $\mathrm{p}=0.042$, age adjusted $\mathrm{p}$ $=0.048$ and age and BMI $\mathrm{p}=0.040)$. No association between another two-SNP haplotype and continuous variable related to obesity or lipid metabolism became apparent.

Although rs7849191 and rs3780378 are located in intronic regions, possible functional implications worth further investigation. The studied variants or even those that are in LD with rs3780378 may affect regulatory regions that modify the expression of genes playing roles as genetic modifiers, therefore we used the program FASTSNP [31] to investigate potential functional significance. The analysis revealed that both rs7849191 and rs3780378, and 7 SNPs in LD with rs3780378 (rs10115312, rs7034753, rs7023146, rs7043371, rs1328917, rs7857730 and rs6476939), may have a possible effect of intronic enhancer.

For identification of regulatory sequences based in evolutionarily conserved noncoding regions we performed a human/mouse whole genome comparison using the BLASTz and 'subsetAxt' programs, as described in the ensembl multicontig view help page. The results indicate that both rs7849191 and rs3780378 and at least 4 SNPs in LD (rs7037207, rs7875908, rs2230724, rs6476939) would be located in conserved regions of $1004 \mathrm{pb}, 9977 \mathrm{pb}, 2433 \mathrm{pb}, 825 \mathrm{pb}$ and 1411 pb respectively.

\section{Discussion}

We examined the association between two SNPs of JAK2 and MS, phenotypes and quantitative traits related to $\mathrm{MS}$ in a sample of 724 unrelated men. Both rs7849191 and rs3780378 were associated with MS reduced risk at levels that take into account multiple testing. A p-value to account for multiple hypothesis testing was taken pragmatically at 0.01 as described in Statistical Analysis section. Also, we observed 
association of rs3780378 with both TG values under 150 $\mathrm{mg} / \mathrm{dl}$ and $\mathrm{HW}$; and we demonstrated differences in TG, TG/HDL-C and LAP between genotypes at levels that take into account multiple testing.

In our study we genotyped only the most significant variants of a gene wide association study conducted by $\mathrm{Ge}$ et al. Some results had been corroborated in our sample. The authors found that subjects homozygous for the major allele of rs3780378 had lower levels of TG in comparison to subjects homozygous or heterozygous for the minor allele; and they also failed to find association between rs3780378 and obesity related phenotypes or measurements of IR. Taking into account the results of both studies, the association between rs3780378 and TG seems to be relevant and deserves further attention. Moreover, in our sample, rs3780378 was associated with categorical and continuous variables related to TG. The authors also reported association with total cholesterol and LDL-C. Furthermore, in their cohort, rs7849191 was associated with continuous variables related to obesity. Although these associations are nominal, we should notice the poor correlation between both results. Such discrepancies are probably due to different allele frequencies or different LD structure in both populations.

We used estimated haplotype frequencies to assess the relationship between variation in a $142.8 \mathrm{~kb}$ region and defined phenotypes using SNP genotypes collected on cases and controls. The effect of combinations of twoSNP haplotype (rs7849191 and rs3780378 in that order) was consistent with single locus analysis. Our results show that carring both protective alleles (haplotype CT), would be associated with MS and TG values under 150 $\mathrm{mg} / \mathrm{dl}$ and HW. Furthermore, haplotype analysis of quantitative metabolic traits seemed to reveal significant differences in TG, TG/HDL-C and LAP between haplotypes. Association with MS was significant at levels that take into account multiple comparisons.

The current results may be related to the role of inflammation in the development of MS and related traits such as HW, elevated TG/HDL-C and elevated LAP. Recent studies suggest that accumulation of inflammatory $\mathrm{T}$-cells in adipose is an early event in obesity and MS [32,33]. We previously demonstrated in a sample selected from the same cross-sectional study, that both TG/HDL-C and LAP, were the majors predictors of MS [34] LAP and TG/HDL-C could be associated with highly lipolytic adipose tissue. Adipose tissue with high levels of lipolysis is an early and critical abnormality in the development of cardiovascular disease, DM2 and MS [35].

Pro-inflammatory cytokines negatively regulate insulin action through phosphorylation of IRS-1 or induction of SOCS expression [36]. JAK2 is the key mediator of cytokine signaling. Several studies have reported cross talk between the insulin receptor kinase and JAK signaling pathways but JAK2 involvement in insulin signaling and function remains to be investigated [37]. Besides, leptin can induce expression of SOCS3 and has been proposed as a possible mechanism for leptin resistance, since it leads to the inhibition of leptin signaling through the JAK2/STAT3 pathway.

The current study has some limitations, the sample size was relatively small and p-values were not corrected for the number of tests performed. This data should be viewed as a preliminary source for future studies including prospective studies with larger sample size and different ethnic groups.

\section{Conclusions}

In conclusion, the present study appears to describe for the first time significant associations of common variants in JAK2 gene with MS and lipid metabolism disorders, such as HW, TG/HDL-C and LAP. These findings could be explained by the role of JAK2 in insulin and/or leptin signaling. The molecular mechanisms that explain the associations observed are still unknown but rs7849191and rs3780378 themselves, or SNPs in LD with rs3780378 may be located in regulatory regions with potential functional effects.

\section{Acknowledgements}

This work was supported by the grant PICT 38343 (ANCyP R. Argentina)

\section{Author details}

${ }^{1}$ Humoral Immunity Institute "Prof. Ricardo A. Margni" (IDEHU), National Research Council (CONICET) \& Chair of Immunology, School of Pharmacy and Biochemistry, University of Buenos Aires (UBA) - Argentina. ${ }^{2}$ Chair of Genetic, Department of Microbiology, Inmunology and Biotecnology, School of Pharmacy and Biochemistry, University of Buenos Aires (UBA) - Argentina. ${ }^{3}$ Laboratory of Lipids and lipoproteins, Department of Clinical Biochemistry, School of Pharmacy and Biochemistry. National Research Council (CONICET) \& University of Buenos Aires (UBA) - Argentina. ${ }^{4}$ Genetics Division, Clinical Hospital "José de San Martín", University of Buenos Aires (UBA) - Argentina.

\section{Authors' contributions}

APS and MLT carried out the molecular genetic studies, participated in the design of the study, performed the statistical analysis and drafted the manuscript. LGR and FDB carried out the biochemical analysis and contributed to the design and coordination of the study. GDF and EP designed the study, obtained samples and edited and approved the final manuscript. All authors read and approved the final manuscript.

\section{Competing interests}

The authors declare that they have no competing interests.

Received: 4 June 2011 Accepted: 20 December 2011 Published: 20 December 2011

\section{References}

1. Reaven GM: Insulin resistance/compensatory hyperinsulinemia, essential hypertension, and cardiovascular disease. J Clin Endocrinol Metab 2003, 88:2399-403.

2. Hotamisligil GS: Inflammation and metabolic disorders. Nature 2006, 444:860-7.

3. Reaven G: The metabolic syndrome or the insulin resistance syndrome? Different names, different concepts, and different goals. Endocrinol Metab Clin North Am 2004, 33:283-303. 
4. Zavaroni I, Bonini L, Gasparini P, Barilli AL, Zuccarelli A, Dall'Aglio E, Delsignore R, Reaven GM: Hyperinsulinemia in a normal population as a predictor of non-insulin-dependent diabetes mellitus, hypertension, and coronary heart disease: the Barilla factor revisited. Metabolism 1999, 48:989-94

5. Zimmet $P$, Alberti KG, Shaw J: Global and societal implications of the diabetes epidemic. Nature 2001, 414:782-7.

6. Rane SG, Reddy EP: Janus kinases: components of multiple signaling pathways. Oncogene 2000, 19:5662-5679.

7. Chen XP, Losman JA, Rothman P: SOCS proteins, regulators of intracellular signaling. Immunity 2000, 13(3):287-90.

8. Howard JK, Flier JS: Attenuation of leptin and insulin signaling by SOCS proteins. Trends Endocrinol Metab 2006, 17(9):365-71.

9. Obici S, Feng Z, Karkanias G, Baskin DG, Rossetti L: Decreasing hypothalamic insulin receptors causes hyperphagia and insulin resistance in rats. Nat Neurosci 2002, 5:566-572.

10. Kamohara S, Burcelin R, Halaas JL, Friedman JM, Charron MJ: Acute stimulation of glucose metabolism in mice by leptin treatment. Nature 1999, 389:374-377

11. Banks AS, Davis SM, Bates SH, Myers MG Jr: Activation of downstream signals by the long form of the leptin receptor. J Biol Chem 2000, 275:14563-14572.

12. Tartaglia LA, Dembski M, Weng X, Deng N, Culpepper J, Devos R, Richards GJ, Campfield LA, Clark FT, Deeds J, Muir C, Sanker S, Moriarty A, Moore KJ, Smutko JS, Mays GG, Wool EA, Monroe CA, Tepper RI: Identification and expression cloning of a leptin receptor, OB-R. Cell 1995, 83(7):1263-71.

13. Campfield LA, Smith FJ, Guisez Y, Devos R, Burn P: Recombinant mouse $\mathrm{OB}$ protein: evidence for a peripheral signal linking adiposity and central neural networks. Science 1995, 269(5223):546-9.

14. Carvalheira JB, Ribeiro EB, Folli F, Velloso LA, Saad MJ: Interaction between leptin and insulin signaling pathways differentially affects JAK-STAT and PI 3-kinase-mediated signaling in rat liver. Biol Chem 2003, 384:151-159.

15. Duan C, Li M, Rui L: SH2-B promotes insulin receptor substrate 1 (IRS1)and IRS2-mediated activation of the phosphatidylinositol 3-kinase pathway in response to leptin. J Biol Chem 2004, 279(42):43684-91.

16. Ge D, Gooljar SB, Kyriakou T, Collins LJ, Swaminathan R, Snieder H, Spector TD, O'Dell SD: Association of common JAK2 variants with body fat, insulin sensitivity and lipid profile. Obesity 2008, , no. 2: 16.

17. Lalouel JM, Rohrwasser A: Power and replication in case-control studies. Am J Hypertens 2002, 15:201.

18. Matthews DR, Hosker JP, Rudenski AS, Naylor BA, Treacher DF, Turner RC: Homeostasis model assessment: insulin resistance and beta-cell function from fasting plasma glucose and insulin concentrations in man. Diabetologia 1985, 28(7):412-9.

19. Friedewald WT, Levy RI, Fredrickson DS: Estimation of concentration of low density lipoprotein cholesterol in plasma without use of the ultracentrifugation. Clin Chem 1972, 18:449-502.

20. Kahn HS: The "lipid accumulation product" performs better than the body mass index for recognizing cardiovascular risk: a population-based comparison. BMC Cardiovasc Disord 2006, 6:5, 2005 Sep 8;5:26. Erratum in: BMC Cardiovasc Disord.

21. Report of a WHO Consultation on Obesity. Obesity, preventing and managing the global epidemic: Ginebra: World Health Organization; 1997.

22. Scott MG, Cleeman J, Daniels SR, Donato KA, Eckel RH, Franklin BA, Gordon DJ, Krauss RM, Savage PJ, Smith SC, Spertus JA, Costa F: Diagnosis and Management of the Metabolic Syndrome An American Heart Association/National Heart, Lung, and Blood Institute Scientific Statement. Circulation 2005, 112:2735-2752.

23. Grundy SM, Cleeman JI, Daniels SR, Donato KA, Eckel RH, Franklin BA, Gordon DJ, Krauss RM, Savage PJ, Smith SC Jr, Spertus JA, Costa F, American Heart Association; National Heart Lung and Blood Institute: Diagnosis and management of the metabolic syndrome: an American Heart Association/National Heart, Lung, and Blood Institute Scientific Statement. Circulation 2005, 112(17):2735-52.

24. American Diabetes Association: Standards of medical care in diabetes2011. Diabetes care 2011, 34(Suppl 1):S11-61.

25. Barrett JC, Fry B, Maller J, Daly MJ: Haploview: analysis and visualization of LD and haplotype maps. Bioinformatics 2005, 21(2):263-5.
26. Skol AD, Scott $L J$, Abecasis GR, Boehnke M: Joint analysis is more efficient than replication-based analysis for two-stage genome-wide association studies. Nat Genet 2006, 38(2):209-13.

27. Stephens M, Donnelly P: A comparison of bayesian methods for haplotype reconstruction from population genotype data. Am J Hum Genet 2003, 73(5):1162-9.

28. Tregouet DA, Barbaux S, Escolano S, Tahri N, Golmard JL, Tiret L, Cambien F: Specific haplotypes of the P-selectin gene are associated with myocardial infarction. Hum Mol Genet 2002, 11:2015-2023.

29. Tregouet DA, Escolano S, Tiret L, Mallet A, Golmard JL: A new algorithm for haplotype-based association analysis: the Stochastic-EM algorithm. Ann Hum Genet 2004, 68:165-177.

30. van den Oord EJ, Sullivan PF: False discoveries and models for gene discovery. Trends Genet 2003, 19:537-542.

31. Yuan HY, Chiou JJ, Tseng WH, Liu CH, Liu CK, Lin YJ, Wang HH, Yao A, Chen YT, Hsu CN: FASTSNP: an always up-to-date and extendable service for SNP function analysis and prioritization. Nucleic Acids Res 2006, 34(Web Server issue):W635-41.

32. Nishimura S, Manabe I, Nagasaki M, Eto K, Yamashita H, Ohsugi M, Otsu M, Hara K, Ueki K, Sugiura S, Yoshimura K, Kadowaki T, Nagai R: CD8+ effector $T$ cells contribute to macrophage recruitment and adipose tissue inflammation in obesity. Nat Med 2009, 15:914-920.

33. Kintscher U, Hartge M, Hess K, Foryst-Ludwig A, Clemenz M, Wabitsch M, Fischer-Posovszky P, Barth TF, Dragun D, Skurk T, Hauner H, Bluher M, Unger T, Wolf AM, Knippschild U, Hombach V, Marx N: Lymphocyte infiltration in visceral adipose tissue: a primary event in adipose tissue inflammation and the development of obesity-mediated insulin resistance. Arterioscler Thromb Vasc Biol 2008, 28:1304-1310.

34. Tellechea ML, Aranguren F, Martínez-Larrad MT, Serrano Ríos M, Taverna MJ, Frechtel GD: Ability of lipid accumulation product to identify metabolic syndrome in healthy men from Buenos Aires. Diabetes Care 2009, 32:e85.

35. Despres JP, Lemieux I, Bergeron J, Pibarot P, Mathieu P, Larose E, Rode's Cabau J, Bertrand OF, Poirier P: Abdominal obesity and the metabolic syndrome: contribution to global cardiometabolic risk. ArteriosclerThrombVasc Biol 2008, 28:1039-1049.

36. Saltiel $A R$, Pessin JE: Insulin signaling pathways in time and space. Trends Cell Biol 2002, 12:65-71.

37. Thirone AC, JeBailey L, Bilan PJ, Klip A: Opposite effect of JAK2 on insulindependent activation of mitogen-activated protein kinases and Akt in muscle cells: possible target to ameliorate insulin resistance. Diabetes 2006, 55(4):942-51.

\section{Pre-publication history}

The pre-publication history for this paper can be accessed here: http://www.biomedcentral.com/1471-2350/12/166/prepub

\section{doi:10.1186/1471-2350-12-166}

Cite this article as: Penas-Steinhardt et al:: Association of common variants in JAK2 gene with reduced risk of metabolic syndrome and related disorders. BMC Medical Genetics 2011 12:166.

\section{Submit your next manuscript to BioMed Central and take full advantage of:}

- Convenient online submission

- Thorough peer review

- No space constraints or color figure charges

- Immediate publication on acceptance

- Inclusion in PubMed, CAS, Scopus and Google Scholar

- Research which is freely available for redistribution 